\title{
PULMONARY DIFFUSING CAPACITY : A COMPARISON OF BREATH-HOLDING AND STEADY STATE METHODS USING CARBON MONOXIDE
}

\author{
By G. H. APTHORP * AND R. MARSHALL $\dagger$ \\ (From the Medical Unit, St. Bartholomew's Hospital, London, England)
}

(Submitted for publication November 11, 1960; accepted May 12, 1960)

Three methods are in current use for measuring the diffusing capacity of the lungs for carbon monoxide (DL). Two of these are steady state methods, and they differ in the methods used to calculate the mean alveolar carbon monoxide tension. Filley, MacIntosh and Wright (1) calculate the alveolar Pco indirectly, assuming the physiological dead space for carbon dioxide to be the same as that for carbon monoxide, while Bates, Boucot and Dormer (2) use the end-tidal Pco as the mean alveolar Pco. The third method is the single breath method of Krogh and Krogh (3) as modified by Ogilvie, Forster, Blakemore and Morton (4). Each method in theory measures the total resistance to gas diffusion offered by the structures that lie between the gas in the alveoli and the hemoglobin within the red cells of the pulmonary capillaries. The results obtained by each method differ in normal subjects; and in disease states, such as emphysema, the differences may be great. While the different results obtained in similar subjects by the two steady state methods can largely be explained by the different methods of estimating the mean alveolar Pco (5), the breath-holding method consistently gives higher results than either of the steady state methods (6). Marshall (7) has recently compared the breath-holding method of measuring DL with a steady state method, using end-tidal samples in a small group of normal subjects and patients with emphysema. He found that, while in normal subjects the end-tidal sample satisfactorily reflected the mean alveolar Pco, in emphysema with impaired intrapulmonary gas mixing, the end-tidal sample overestimates the mean alveolar Pco and therefore gives falsely low results for the diffusing capacity. These results

\footnotetext{
* Cattlin and Cooper Research Scholar, St. Bartholomew's Hospital.

$\dagger$ Present address: Nuffield Department of Surgery, Radcliffe Infirmary, Oxford.
}

throw doubt on the validity of the end-tidal steady state method of measuring diffusing capacity in subjects with other cardiopulmonary diseases who also have impaired pulmonary gas mixing.

The present study was made 1) to compare the single breath and steady state methods in a large group of subjects with widely varying intrapulmonary gas mixing; and 2) since abnormalities of intrapulmonary gas mixing cannot explain the differences that occur between the two methods in normal subjects, a study was made of the variations in the type of breathing which might influence the results of the steady state method in normal subjects.

\section{METHODS}

The stcady state method used was that of Bates and co-workers (2) but the apparatus was modified in a number of details. The valve assembly consisted of single inspiratory and expiratory valves set in $2.5 \mathrm{~cm}$-bore metal tubing in order to reduce the dead space and allow end-tidal samples to be obtained with smaller tidal volumes than were possible with the original apparatus. An automatic end-tidal sampler, triggered by a change in pressure at the mouthpiece, snatched a $35 \mathrm{ml}$ sample at the end of each breath. During the test the subject breathed 0.125 per cent carbon monoxide in air; 1.5 minutes was allowed for the subject to reach a steady state and the expired gas was collected for a further 2 minutes during which time end-tidal samples were taken. The $\mathrm{CO}$ concentration in the inspired, mixed expired and end-tidal samples was measured by an infrared analyzer. Oxygen and carbon dioxide in the expired gas were measured by the Haldane method.

The pulmonary capillary carbon monoxide tension cannot be ignored in the steady state method. Subjects with a normal or high diffusing capacity have a considerable increase in blood carbon monoxide during the test, and unless this is allowed for, it may lower the calculated diffusing capacity by as much as 20 per cent (8). Nonsmokers were assumed to have a negligible level of blood $\mathrm{CO}$ initially, and measurements of the pulmonary capillary blood $\mathrm{CO}$ tension were made only after the tests. In smokers the measurements were made both before and after. We used a modification of the method of 
Sjöstrand (9) which has been described elsewhere (10). The subject breathed oxygen for 3 minutes from an open circuit to wash out the nitrogen from the lungs. He then took a deep breath in and exhaled through a soda lime canister into an empty rubber bag from which he rebreathed for a further 3 minutes. The content of the bag was then analyzed for carbon dioxide, oxygen and carbon monoxide. The carbon monoxide tension of the blood, at the oxygen tension in the lungs during the test, was then calculated from the carbon monoxide and oxygen tensions in the rebreathing bag by the method described by Forster and co-workers (11). The steady state $D_{L}$ is calculated from the equation:

$$
\mathrm{DL}=\frac{\mathrm{ml} \text { CO taken up in } 1 \text { minute }}{(\mathrm{ETCO}-\mathrm{PBCO}) \times(\mathrm{B}-47)}
$$

where ETco is the fraction of $\mathrm{CO}$ in the end-tidal sample, $\mathrm{B}$ is the atmospheric pressure in $\mathrm{mm} \mathrm{Hg}$, and $\mathrm{PBco}$ is the calculated fraction of $\mathrm{CO}$ in equilibrium with the pulmonary capillary blood; i.e., $\mathrm{CO} \%$ in equilibrated bag $\times$ calculated end-tidal $\mathrm{O}_{2} \% / \mathrm{O}_{2} \%$ in equilibrated bag.

The measurements on patients at rest, for reasons explained below, were made with the patient hyperventilating to maintain a tidal volume of at least $600 \mathrm{ml}$ (STPD) and a respiratory rate of over 12 per minute. Subjects with tidal volumes or respiratory rates below these limits were excluded from the series. Measurements were made on exercise with the subjects walking on a motor-driven treadmill at a speed to cause moderate dyspnea.

The single breath method used was that described by Ogilvie and colleagues (4). An inspired mixture containing 14 per cent helium, 0.125 per cent carbon monoxide, 20 per cent oxygen and the remainder nitrogen was used. The back pressure of $\mathrm{CO}$ in the blood was calculated as for the steady state method. Two estimations of DL were made, with a few minutes between each, and the mean of the two results taken.

Lung volumes and intrapulmonary gas mixing were measured by the helium closed-circuit technique with the apparatus described by Bates and Christie (12). The normal limits of the mixing efficiency index by this method are considered to be 50 to 100 per cent.

Subjects and procedure. The normal subjects were medical students and laboratory staff. All patients attending the laboratory for pulmonary function tests during the period of the study are included in the series; 16 normal subjects and 125 patients with cardiopulmonary disease were studied. The order of investigation follows : 1) the lung volumes and intrapulmonary gas mixing were measured; 2) the basal level of $\mathrm{CO}$ in the blood was measured in smokers; 3) two estimations of the single breath $\mathrm{DL}_{\mathrm{L}}$ were made; 4) the $\mathrm{CO}$ in the blood was again measured; 5) the steady state $D_{L}$ was measured at rest (during this estimation the tidal volume was recorded by a low resistance dry-gas meter on the inspiratory side of the circuit so that tidal volume was immediately read off and the patient was encouraged to increase his tidal volume to about one-third of his vital capacity); 6) the steady state Dr. was measured during exercise; 7) the $\mathrm{CO}$ in the blood was again measured.

The steady state DL was also measured in 3 normal subjects at varying tidal volumes both at rest and on exercise and in 4 of the subjects at varying respiratory rates at rest. All volumes are recorded at STPD.

\section{RESULTS}

The relationship of steady state $D L$, ventilation. and exercise in normal subjects. The steady state DL was measured in three normal subjects who breathed at a fixed rate of 12 breaths per minute to a metronome and varied their tidal volumes. The results in all three subjects were similar, and detailed results in Subject GHA at rest are shown in Figure 1. In this subject the steady

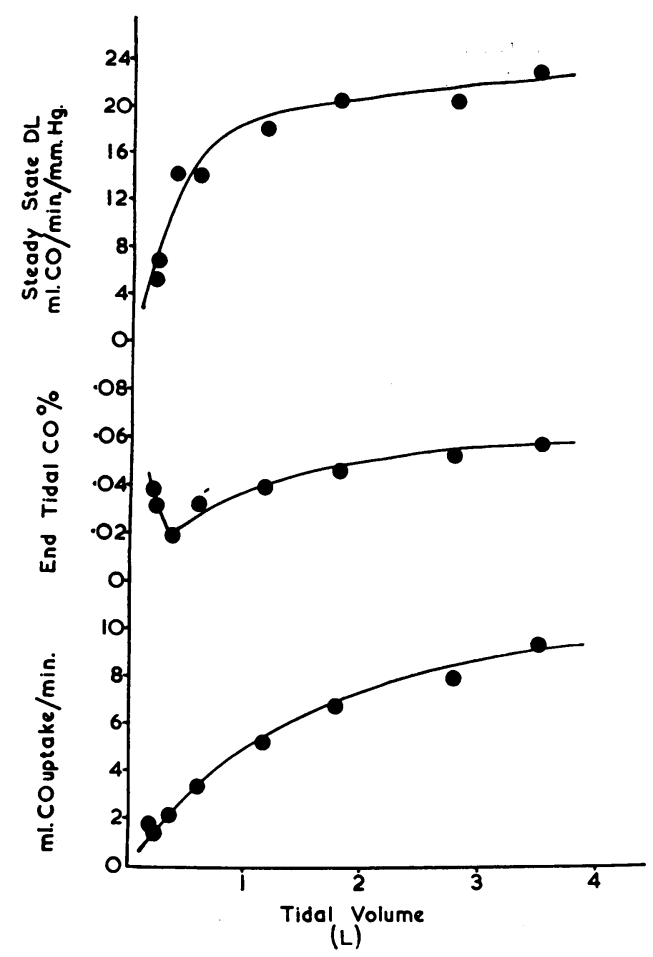

Fig. 1. Effect of tidal volume on steady state Dl, end-tidal CO\%, and CO uptake; Subject GHA. Steady state $D_{L}$ measured at a constant respiratory rate of 12 per minute and varying tidal volume. The lower graph shows the steady rise in the volume of $\mathrm{CO}$ taken up as the tidal volume increases. The middle graph shows the rise of end-tidal $\mathrm{CO}$ as the tidal volume decreases. The rise in $\mathrm{CO} \%$ at low tidal volumes is due to contamination with dead space gas ( $\mathrm{CO} \%$ of dead space $=$ inspired $\mathrm{CO} \%=0.125 \% \mathrm{CO})$. The quotient of these two, the steady state $D_{L}$, shows a rapid rise until a tidal volume of about $1 \mathrm{~L}$ is reached and after that a slowly rising plateau. 


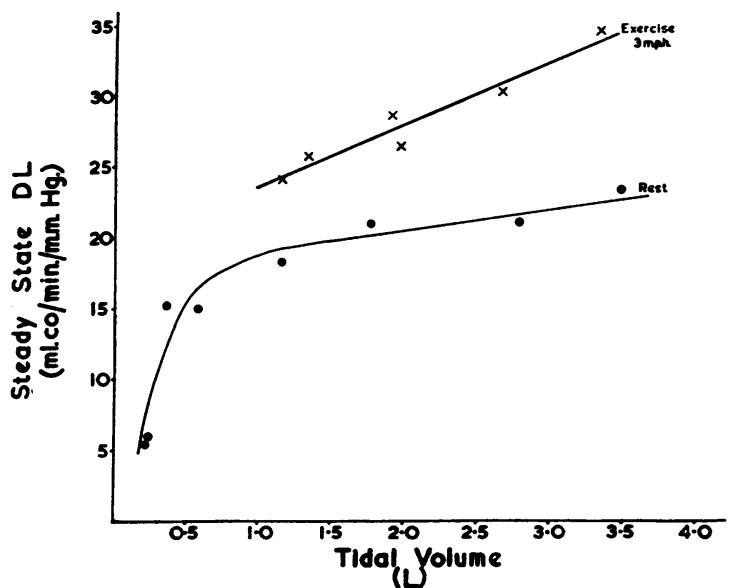

Fig. 2. The EFFEct of tidal volume on STEAdy STATE De at Rest and during exercise; SubJect GHA. Steady state $\mathrm{DL}_{\mathrm{L}}$ at rest and during steady exercise (3 $\mathrm{mph}$ ) on treadmill. The subject was breathing at a steady 12 breaths per minute and varying tidal volume.

state $D_{L}$ rose rapidly to reach $15 \mathrm{ml}$ per minute per $\mathrm{mm} \mathrm{Hg}$ at a tidal volume of $600 \mathrm{ml}$; thereafter there was a more gradual rise in $\mathrm{DL}_{\mathrm{L}}$ as the alveolar ventilation increased, and at a tidal volume of $3,700 \mathrm{ml}$ the DL was $23 \mathrm{ml}$ per minute per $\mathrm{mm} \mathrm{Hg}$. The volume of $\mathrm{CO}$ taken up per minute increased from $2 \mathrm{ml}$ per minute when the tidal volume was a few hundred $\mathrm{ml}$ to about $9 \mathrm{ml}$ per minute at the greatest tidal volume. The increase in end-tidal CO per cent and the fall in $\mathrm{DL}_{\mathrm{L}}$ at low tidal volumes are due to contamination of the end-tidal sample with dead space carbon monoxide. From the results of these experiments it was concluded that a tidal volume of $600 \mathrm{ml}$ was the minimum necessary for end-tidal sampling, and the steady state DL varied with the alveolar volume or alveolar ventilation at which it was measured.

A similar rise of $D_{L}$ with increasing tidal volume was also found during exercise. Two subjects exercised at a steady speed of $3 \mathrm{mph}$ and again breathed to a metronome at 12 breaths per minute. The results in two subjects (GHA and RM) were very similar and Figure 2 shows the results in Subject GHA. The most comfortable tidal volume at this respiratory rate was about $0.5 \mathrm{~L}$ at rest and about $2 \mathrm{~L}$ on exercise. The difference between $D_{L}$ measured during quiet breathing at rest $\left(D_{L}=15 \mathrm{ml} / \mathrm{min} / \mathrm{mm} \mathrm{Hg}\right.$ with a tidal volume of $0.5 \mathrm{~L}$ ) and that on exercise ( $\mathrm{DL}_{\mathrm{L}}=27 \mathrm{ml} / \mathrm{min} / \mathrm{mm} \mathrm{Hg}$ with a tidal volume of $2.0 \mathrm{~L}$ ) is $12 \mathrm{ml}$ per minute per $\mathrm{mm} \mathrm{Hg}$. Of this increase, $5 \mathrm{ml}$ per minute per $\mathrm{mm} \mathrm{Hg}$ can be produced at rest by increasing the tidal volume to $2.0 \mathrm{~L}$; the other $7 \mathrm{ml}$ per minute per $\mathrm{mm} \mathrm{Hg}$ is presumably the result of exercise.

In a second series of experiments nine normal subjects were examined, and both the steady state and single breath DL measured. The steady state DL was measured at rest during "quiet" breathing, during hyperventilation at the same respiratory rate (11 per minute) and during exercise. The tidal volume during the "quiet" respiration was at least $600 \mathrm{ml}$, and during hyperventilation it was as deep as possible. During exercise the subject breathed at his most comfortable rate and

TABLE I

Comparison of steady state $D_{L}$ measured during quiet breathing and hyperventilation with single breath $D_{L}$ in 9 normal subjects all breathing at rest to a metronome set at 11 breaths per minute*

\begin{tabular}{|c|c|c|c|c|c|c|c|c|c|c|c|c|c|c|c|c|c|c|}
\hline \multirow[b]{3}{*}{ Subject } & \multirow[b]{3}{*}{ Age } & \multirow[b]{3}{*}{ Sex } & \multirow[b]{3}{*}{ SA } & \multirow[b]{3}{*}{$\begin{array}{l}\text { Vital } \\
\text { capacity }\end{array}$} & \multirow{3}{*}{$\begin{array}{c}\text { Single } \\
\text { breath } \\
\text { DL }\end{array}$} & \multicolumn{10}{|c|}{ Steady state DL } & \multirow{2}{*}{\multicolumn{3}{|c|}{$\begin{array}{c}\text { Fraction } \\
\text { Steady state DL }\end{array}$}} \\
\hline & & & & & & \multicolumn{3}{|c|}{ A. Quiet breathing } & \multicolumn{3}{|c|}{ B. Hyperventilation } & \multicolumn{4}{|c|}{ C. Exercise } & & & \\
\hline & & & & & & VT & $\begin{array}{l}\text { Resp. } \\
\text { rate }\end{array}$ & DL & VT & $\begin{array}{l}\text { Resp. } \\
\text { rate }\end{array}$ & DL & Speed & VT & $\begin{array}{l}\text { Resp. } \\
\text { rate }\end{array}$ & DL & $\begin{array}{l}\text { Single } \\
\mathrm{A}\end{array}$ & B & C \\
\hline & & & $m^{2}$ & $m l$ & & & & & & & & $m p h$ & & & & & & \\
\hline $\begin{array}{l}\text { RM } \\
\text { GHA } \\
\text { JSM } \\
\text { RDW } \\
\text { CPR } \\
\text { JAW } \\
\text { MEU } \\
\text { MC } \\
\text { PJB }\end{array}$ & $\begin{array}{l}34 \\
34 \\
22 \\
25 \\
21 \\
20 \\
33 \\
22 \\
32\end{array}$ & $\begin{array}{l}\mathbf{M} \\
\mathbf{M} \\
\mathbf{M} \\
\mathbf{M} \\
\mathbf{M} \\
\mathbf{F} \\
\mathbf{F} \\
\mathbf{F} \\
\mathbf{M}\end{array}$ & $\begin{array}{l}1.95 \\
1.95 \\
1.65 \\
2.31 \\
1.93 \\
1.61 \\
1.74 \\
1.50 \\
1.97\end{array}$ & $\begin{array}{l}4,540 \\
4,300 \\
3,468 \\
5,730 \\
5,875 \\
3,275 \\
3,500 \\
2,900 \\
4,500\end{array}$ & $\begin{array}{l}34.7 \\
31.0 \\
36.2 \\
28.9 \\
56.0 \\
29.2 \\
27.5 \\
24.0 \\
34.0\end{array}$ & $\begin{array}{r}865 \\
660 \\
1,052 \\
795 \\
640 \\
993 \\
1,070 \\
505\end{array}$ & $\begin{array}{l}10 \\
10 \\
10 \\
12.5 \\
12 \\
11 \\
11 \\
13\end{array}$ & $\begin{array}{l}22.0 \\
17.1 \\
20.0 \\
32.6 \\
20.3 \\
19.0 \\
23.1 \\
26.8\end{array}$ & $\begin{array}{l}2,510 \\
3,500 \\
1,738 \\
2,995 \\
3,450 \\
1,880 \\
1,918 \\
1,921 \\
1,766\end{array}$ & $\begin{array}{l}10 \\
12 \\
10 \\
10.5 \\
10 \\
12 \\
11 \\
11 \\
11\end{array}$ & $\begin{array}{l}29.0 \\
24.0 \\
33.0 \\
32.3 \\
53.7 \\
24.5 \\
27.3 \\
27.0 \\
32.4\end{array}$ & $\begin{array}{l}3.5 \\
3 \\
3 \\
3 \\
3 \\
2.5 \\
2.5 \\
3 \\
3\end{array}$ & $\begin{array}{r}1,060 \\
1,045 \\
760 \\
1,705 \\
1,540 \\
757 \\
1,520 \\
1,420 \\
1,382\end{array}$ & $\begin{array}{c}21 \\
17 \\
24 \\
14 \\
16 \\
15 \\
14 \\
9.0 \\
14\end{array}$ & $\begin{array}{l}32.6 \\
31.4 \\
42.6 \\
34.0 \\
46.0 \\
25.4 \\
35.7 \\
37.0 \\
43.6\end{array}$ & $\begin{array}{l}0.64 \\
0.55 \\
0.69 \\
0.58 \\
0.70 \\
0.69 \\
0.96 \\
0.79\end{array}$ & $\begin{array}{l}0.84 \\
0.78 \\
0.91 \\
1.12 \\
0.96 \\
0.84 \\
0.99 \\
1.13 \\
0.95\end{array}$ & $\begin{array}{l}0.94 \\
1.01 \\
1.18 \\
1.18 \\
0.82 \\
0.87 \\
1.31 \\
1.54 \\
1.28\end{array}$ \\
\hline $\begin{array}{l}\text { Mean } \\
\text { figures }\end{array}$ & 27 & & 1.85 & 4,220 & 33.5 & 822 & 11 & 22.6 & 2,330 & 10.7 & 32.0 & 3 & 1,243 & 16 & 36.5 & 0.70 & 0.95 & 1.1 \\
\hline
\end{tabular}

* SA = surface area in square meters; $\mathrm{VT}=$ tidal volume in $\mathrm{ml}$; resp. rate =respiratory rate; $\mathrm{A}=$ during quiet breathing at rest; $\mathrm{B}=\mathrm{during}$ hyperventilation at rest; $C=$ during exercise. All volumes measured STPD. 
TABLE II

The effect of increase in respiratory rate at constant tidal volume on steady state $D_{L}$

\begin{tabular}{|c|c|c|c|c|c|c|c|c|}
\hline Subject & Sex & Age & $\begin{array}{l}\text { Surface } \\
\text { area }\end{array}$ & Respirations & $\begin{array}{c}\text { Tidal } \\
\text { volume }\end{array}$ & $\begin{array}{l}\text { Minute } \\
\text { volume }\end{array}$ & $\begin{array}{c}\text { Steady } \\
\text { state DL }\end{array}$ & \\
\hline & & & $m^{2}$ & rate/min & $m l$ & $L / \min$ & ${ }_{m m ~}^{m l \mathrm{CO} / \mathrm{min}} /$ & \\
\hline $\mathrm{RM}$ & $\mathbf{M}$ & 34 & 1.95 & $\begin{array}{l}10 \\
20.6 \\
26.3\end{array}$ & $\begin{array}{l}865 \\
850 \\
850\end{array}$ & $\begin{array}{r}8.6 \\
17.5 \\
22.4\end{array}$ & $\begin{array}{l}22.0 \\
22.5 \\
20.0\end{array}$ & ' \\
\hline GHA & $\mathbf{M}$ & 34 & 1.95 & $\begin{array}{r}9.5 \\
15.0 \\
25.5\end{array}$ & $\begin{array}{l}2,150 \\
2,500 \\
2,060\end{array}$ & $\begin{array}{l}20.2 \\
37.6 \\
52.6\end{array}$ & $\begin{array}{l}33.0 \\
25.0 \\
25.3\end{array}$ & \\
\hline RW & $\mathbf{M}$ & 26 & 2.30 & $\begin{array}{r}8.0 \\
17.4 \\
24.3\end{array}$ & $\begin{array}{l}2,290 \\
2,170 \\
2,270\end{array}$ & $\begin{array}{l}17.7 \\
37.8 \\
55.1\end{array}$ & $\begin{array}{l}52.0 \\
46.0 \\
45.0\end{array}$ & \\
\hline MH & $\mathrm{F}$ & 30 & 1.69 & $\begin{array}{l}10.2 \\
18.6 \\
31.4\end{array}$ & $\begin{array}{l}1,100 \\
1,270 \\
1,260\end{array}$ & $\begin{array}{l}11.2 \\
23.6 \\
39.5\end{array}$ & $\begin{array}{l}22.2 \\
17.3 \\
18.9\end{array}$ & \\
\hline
\end{tabular}

tidal volume. The results of the experiments are shown in Table I. A rise in the steady state DL occurred in all subjects during hyperventilation, and during hyperventilation the steady state $D_{L}$ and the single breath $D_{L}$ became approximately equal. During quiet breathing the mean steady

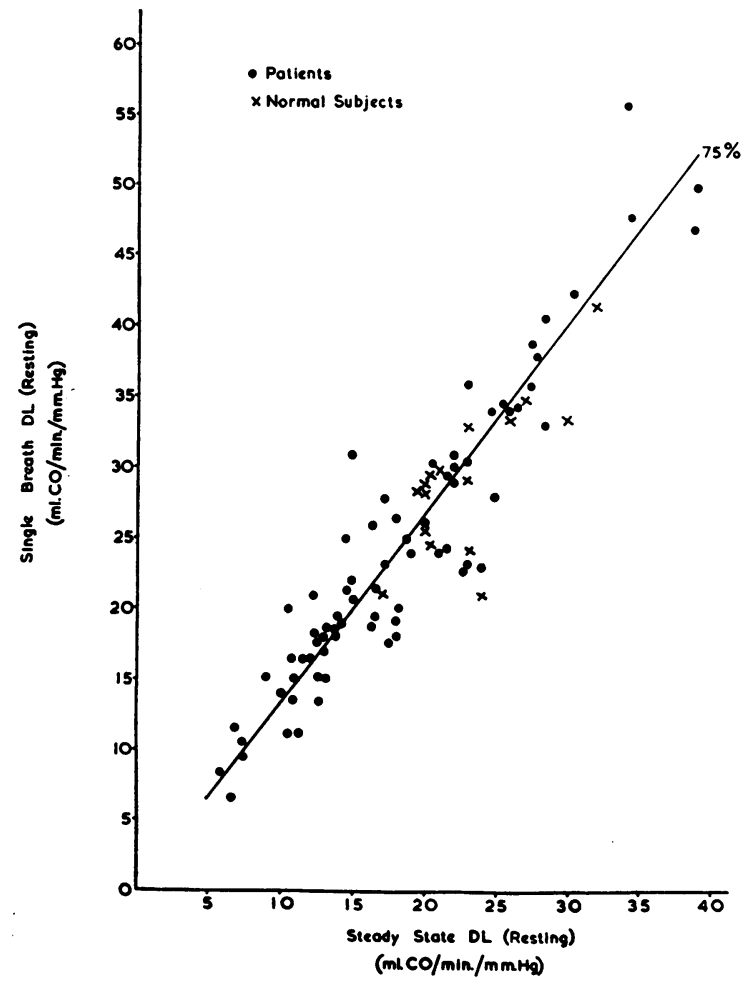

Fig. 3. Steady state Dl plotted against single BREATH DL IN SUBJECTS WITH NORMAL INTRAPULMONARY GAS MIXING. Mean relationship $75 \%$. state DL was 70 per cent of the mean single breath $\mathrm{DL}$, while during hyperventilation at the same respiratory rate the steady state $D_{L}$ was 95 per cent of the single breath $D_{L}$. The steady state

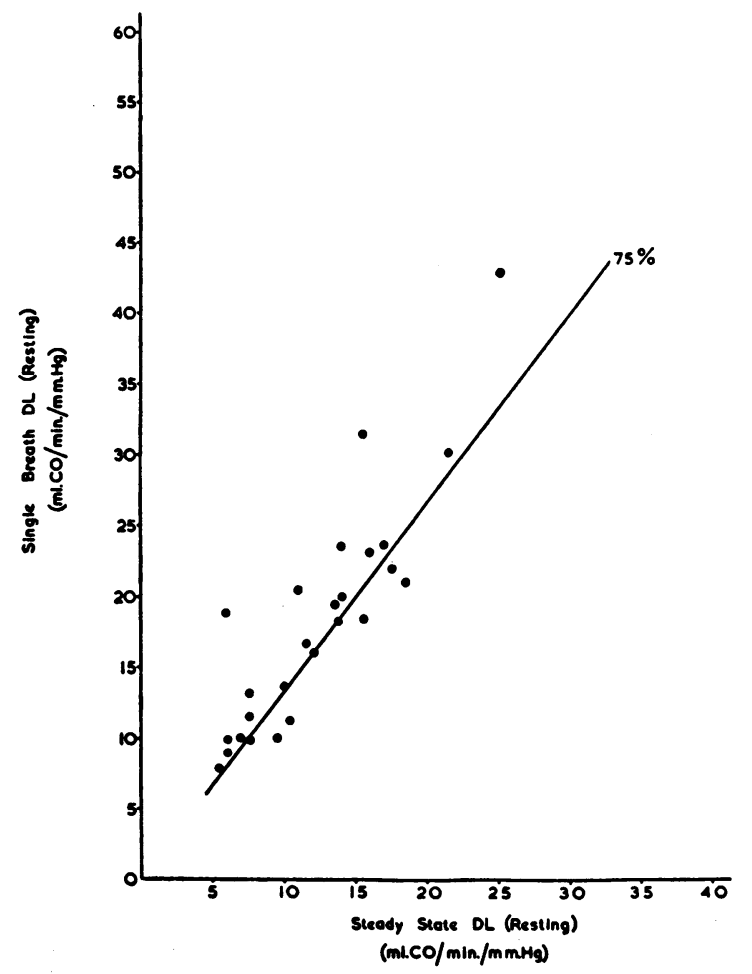

Fig. 4. Steady state Dl plotted against single BREATH DL IN PATIENTS WITH IMPAIRED MIXING BUT EXCLUDING THOSE With EMPHYSEMA. The line indicating the $75 \%$ relationship which exists in normal subjects is shown for comparison. 
TABLE III

The relationship between sleady slate $D_{L}$ and single breath $D_{L}$ in subjecls with a normal mixing cfficiency, patients with impaired mixing but no emphysema, and patients with emphysema

\begin{tabular}{|c|c|c|c|c|c|c|c|}
\hline \multirow[b]{3}{*}{ Group } & \multirow[b]{3}{*}{ Subjects } & \multirow{3}{*}{$\begin{array}{l}\text { Helium } \\
\text { mixing } \\
\text { index } \\
\text { within } \\
\text { range }\end{array}$} & \multirow{3}{*}{$\begin{array}{c}\text { Mean } \\
\text { helium } \\
\text { mixing }\end{array}$} & \multirow{2}{*}{\multicolumn{2}{|c|}{$\begin{array}{c}\text { Fraction } \\
\text { Steady state DL }\end{array}$}} & \multirow{3}{*}{$\begin{array}{l}\text { Mean } \\
\text { rate of } \\
\text { exercise }\end{array}$} & \multirow{3}{*}{$\begin{array}{c}\text { Mean } \\
\text { oxygen } \\
\text { consumption } \\
\text { during } \\
\text { exercise }\end{array}$} \\
\hline & & & & & & & \\
\hline & & & & Resting & Exercise & & \\
\hline \multirow{3}{*}{$\begin{array}{l}\text { 1. Normal subjects } \\
\text { Patients with normal } \\
\text { mixing }\end{array}$} & no. & $\%$ & $\%$ & \multirow{3}{*}{$\left.{ }^{0.72}\right\}_{0.75}$} & \multirow{3}{*}{1.09} & $m p h$ & $m l / \min$ \\
\hline & 16 & $50-100$ & 83 & & & 2.9 & 1,050 \\
\hline & 74 & $50-100$ & 71 & & & 2.0 & 913 \\
\hline $\begin{array}{l}\text { 2. Patients with impaired } \\
\text { mixing but no evidence } \\
\text { of emphysema }\end{array}$ & 26 & $0-49$ & 36 & 0.66 & 0.91 & 1.7 & 766 \\
\hline 3. Emphysema & 25 & $0-49$ & 29 & 0.34 & 0.41 & 0.8 & 714 \\
\hline
\end{tabular}

DL on exercise was higher than during hyperventilation at rest in all but one case.

In four subjects the steady state DL was measured at a steady tidal volume and varying respiratory rates. The diffusing capacity was not related to the rate of breathing or the minute volume. The results are summarized in Table II.

A comparison of steady state and single breath methods in patients with cardiac or pulmonary disease. The 125 patients and 16 normal subjects were divided into three groups.

Group 1, subjects with a mixing efficiency of 50 per cent or more: 16 normal subjects and 74 patients.

Group 2, subjects, excluding those with chronic obstructive emphysema, whose mixing efficiency was below 50 per cent : 26 patients.

Group 3, subjects with a clinical diagnosis of chronic obstructive emphysema: 25 patients, all with a mixing efficiency of less than 50 per cent.

The details of the composition of each group and the mean figure for intrapulmonary gas mixing are shown in Table III, together with the mean oxygen consumption at rest and during exercise, and also the rate of exercise. Groups 1 and 2 were largely composed of patients with rheumatic heart disease, congenital heart disease and sarcoidosis but included some patients with thyrotoxicosis and some with asthma. The lowest DL's were recorded in patients with emphysema or with alveolar-capillary block syndrome (13) due to sarcoidosis, metastatic carcinoma or idiopathic pulmonary fibrosis. The highest figures were obtained in patients with congenital heart disease with increased pulmonary blood flow. Most of these patients had atrial septal defects with left to right shunts. All the patients in group 3 suffered from chronic obstructive emphysema. The diagnosis was made on the clinical and radiological findings before they were referred for respiratory function studies.

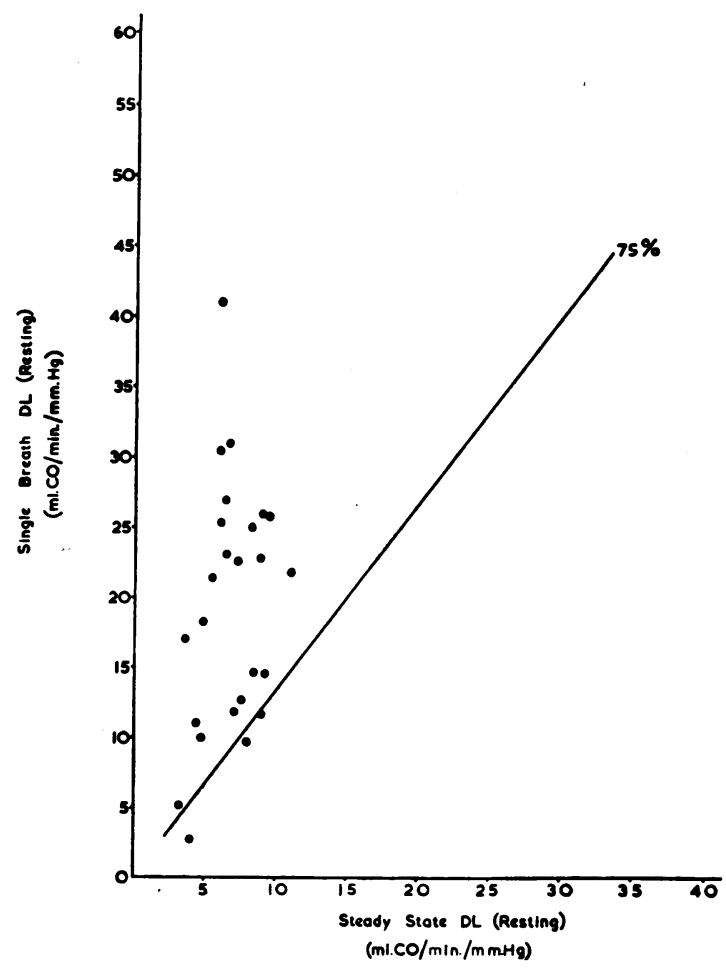

Fig. 5. Steady state Dl plotted against Single BREATH DL IN SUBJECTS WITH EMPHYSEMA. The line indicating the $75 \%$ relationship which exists in normal subjects is shown for comparison. 
The single breath $D_{1}$, was plotted against the steady state DL separately in each group, and the results at rest are shown in Figures 3, 4 and 5. and during exercise in Figures 6 and 7. The scale is identical in each case. The relationship between the two measurements of $\mathrm{DL}_{\mathrm{L}}$ was calculated by the method of least squares. Figure 3 shows the results in group 1 , which was composed of all subjects with normal intrapulmonary gas mixing. The steady state figure was 78 per cent of the single breath figure for the group of 16 normal subjects, and 74 per cent for the 74 patients with normal intrapulmonary gas mixing. The mean figure for the whole group was 75 per cent. In group 2, which includes all patients with impaired intrapulmonary gas mixing, but with no clinical evidence of emphysema, the mean steady state DL was 66 per cent of the single breath DL (Figure 4).

The mean pulmonary gas mixing index of group 3 (29 per cent) is comparable with that of group 2 (36 per cent), but in group 3 the single breath and steady state methods give results that bear no relationship to each other (Figure 5). All the patients with emphysema showed a steady state DL below $10 \mathrm{ml}$ per minute per $\mathrm{mm} \mathrm{Hg}$, while the corresponding single breath $\mathrm{DL}_{\mathrm{L}}$ varies between 3 and $42 \mathrm{ml}$ per minute per $\mathrm{mm}$ $\mathrm{Hg}$. The finding that patients with clinical emphysema have a steady state DL below $10 \mathrm{ml}$ per minute per $\mathrm{mm} \mathrm{Hg}$ is in agreement with the results of Bates, Knott and Christie (14) who used the same method.

\section{DISCUSSION}

A rise in steady state DL was found when normal subjects hyperventilated. This is in line with previous reported work. Ross, Frayser and Hickam (15) and Turino, Brandfonbrener and Fishman (16) using the Filley method, and MacNamara, Prime and Sinclair (17) using the Bates method of measuring the steady state Dr, all found a rise in DL when subjects hyperventilated. In this series, when normal subjects hyperventilated by progressively increasing their tidal volume while keeping the respiratory rate unchanged, a progressive rise in DL occurred (Figure 1); but when the subjects hyperventilated by progressively increasing the respiratory rate while keeping the tidal volume steady, no rise in DL occurred (Table

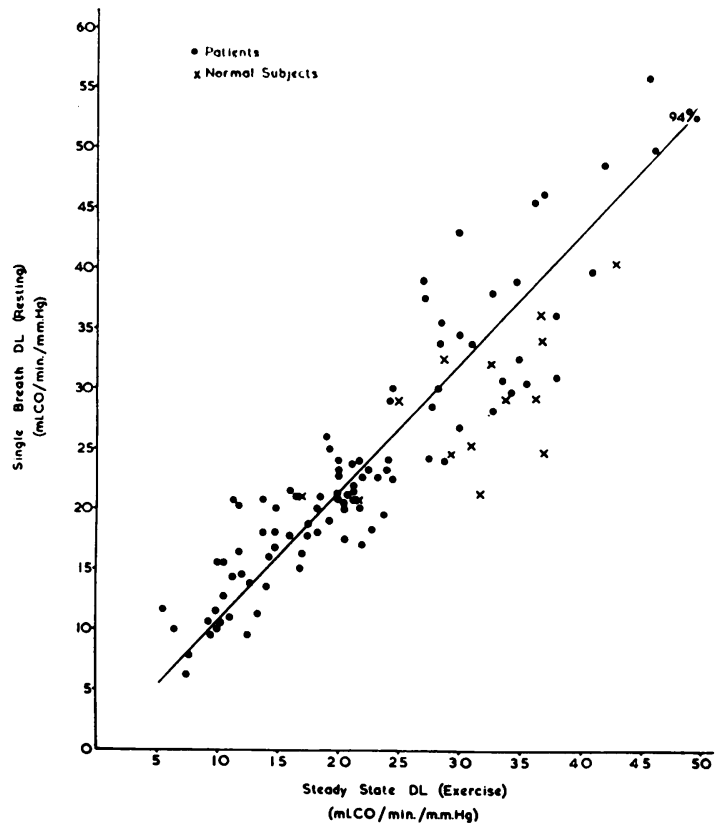

Fig. 6. Steady state Dl during exercise plotted Against THE RESTing SINGLE bReAth REAding. Mean relationship $94 \%$. The graph contains all subjects except those with emphysema.

II). This suggests that the DL varies with the alveolar volume at which it is measured rather than with the alveolar ventilation.

There seems little doubt that DL measured by the single breath method also varies with the alveolar volume. Although Ogilvie and colleagues (4) found $D_{L}$ varied little at different alveolar volumes, Marks, Cugell, Cadigan and Gaensler (6) and Shephard (18) found DL at full inspiration to be up to 50 per cent greater than $D_{L}$ measured at the functional residual capacity, while McGrath and Thomson (19), under similar circumstances, found a mean increase in DL of 31 per cent in eight normal subjects. In a previous study Marshall (7) measured the single breath DL at varying alveolar volumes and showed that DL decreased in such a way that, when the breath was held at the functional residual volume, the single breath De became approximately equal to the steady state Du using end-tidal samples.

In this series there was good agreement between the resting steady state DL measured at maximal tidal volume and the resting single breath $D_{L}$ (Table I). These findings suggest that there is no fundamental difference between the two methods in normal subjects. The increase in $\mathrm{DL}_{\mathrm{L}}$ on hyper- 
ventilation may be due to an increase in the pulmonary capillary blood volume in association with an increased alveolar gas volume and, therefore, a larger blood gas interface. This suggests that the resting single breath $D_{L}$ measured at maximal inspiration and the resting steady state DL measured on maximal hyperventilation are equal, and both reflect the maximal diffusing capacity of the lungs for carbon monoxide in the resting subject.

The steady state DL on exercise was higher than the hyperventilation $D_{L}$ in all but one subject, and higher than the single breath DL in six of the nine subjects. Although the exercise DL obtained in these subjects was not usually equaled during hyperventilation or when measured by the single breath method, the mean exercise DL was only 11 per cent greater than the resting single breath DL. Ross (15), and Turino (16), and their associates made observations at rest and during exercise, using the Filley method. They showed that in the series as a whole, the increase in DL on exercise was no greater than that produced by an equivalent degree of hyperventilation at rest. In the present study, repeated measurements on three subjects (the results on one of

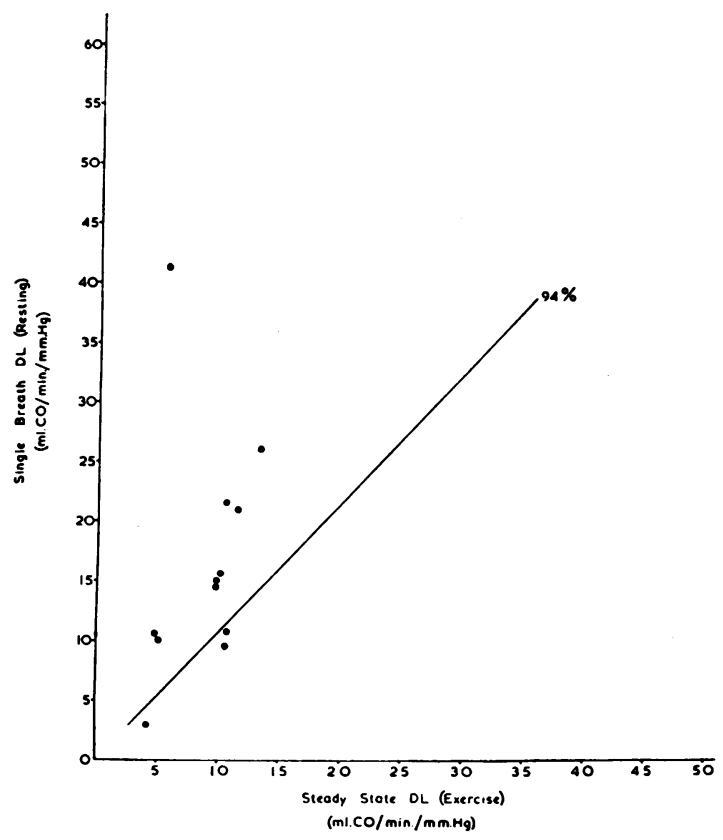

Fig. 7. Steady state Dl during exercise plotted AGAINST THE RESTING SINGLE BREATH DL IN 12 CASES OF EMPHYSEMA. The line indicating the $94 \%$ relationship which existed in all other subjects is shown for comparison. whom are shown in Figure 1) have shown that exercise produces an increase in DL, measured by the steady state method, which is greater than that which can be accounted for by the hyperventilation alone. This is in keeping with the findings of MacNamara and co-workers (17) who also used the Bates method of measuring DL.

The diffusing capacity is not a constant but varies with the alveolar volume at which it is measured, and it is clearly important to control the tidal volume at which $D_{L}$ is measured if the results are not to be misleading. In this context the single breath method has the advantage that the alveolar volume at which it is measured is easily fixed at maximal inspiration, while hyperventilation in the untrained subject at rest may result in irregular tidal volumes and an unreliable figure for DL. Measurement of the steady state DL during exercise overcomes this difficulty, but the result must then be related to the rate of work (2) or oxygen consumption (20) and functional residual volume (2) or surface area.

The general relationship between the steady state and single breath $D_{L}$ in this series of 141 subjects is similar to that obtained by Marks and co-workers (6) who found the Filley steady state method gave results about two-thirds of the single breath DL.

The patients in group 1, with cardiac or respiratory disease but normal intrapulmonary gas mixing, behaved similarly to the normal subjects, the steady state DL being equal to approximately 75 per cent of the single breath DL (Figure 3 ).

The difference in the ratio of steady state $D_{L}$ to single breath DL in group 1 (74 per cent) compared with group 2 ( 66 per cent) may be due to a number of factors. Patients in group 2 were more incapacitated than those in group 1 (Table III) and breathed at a smaller tidal volume. Borderline cases such as one with severe persistent asthma and widespread cystic bronchiectasis (steady state De 4.6 , single breath DL $18 \mathrm{ml}$ $\mathrm{CO} / \mathrm{min} / \mathrm{mm} \mathrm{Hg}$ ) were included in group 2 rather than 3. In addition, it is likely that in the presence of impaired intrapulmonary gas mixing the steady state $\mathrm{DL}$ is too low because of endtidal sampling errors. This point is discussed further below, but the maximal effect of inaccurate end-tidal sampling in group 2 is to lower the steady state Dr. by only 10 per cent. 
The difference in the ratio of DL calculated by the two methods in group 2 (patients with impaired intrapulmonary gas mixing) and group 3 (patients with emphysema) is more interesting. Although the helium mixing index is similar in both groups, the steady state and single breath DL bear no relation to each other in patients with emphysema. The reasons for this may be:

1. The single breath DL is too high in these patients. The single breath $\mathrm{DL}_{\mathrm{L}}$ is calculated from the alveolar volume obtained by adding the inspired volume to the residual volume measured by the helium equilibration technique. In patients with unequal gas mixing this volume $\left(\mathrm{V}_{\text {eq }}\right)$ is greater than that calculated from the dilution of helium inspired in the single breath test $\left(\mathrm{V}_{\mathrm{sb}}\right)$. The alveolar volume $\mathrm{V}_{\mathrm{sb}}$ is only an approximate measure of the volume ventilated by the single breath, because the expired sample collected may not represent the mean helium concentration in the lungs; the highest concentrations of helium are discarded with the dead space gas, and the less well ventilated parts of the lungs contribute only a small volume of the collected sample. In practice, the single breath DL calculated from $\mathrm{V}_{\mathbf{s b}}$ is reduced to 95 per cent of the normally calculated single breath DL in patients in group 2. The patients with emphysema (group 3 ) have a mean single breath DL calculated from $V_{\mathbf{s b}}$ which is 70 per cent of the normal single breath DL. Even when this reduced single breath $D_{L}$ is taken into consideration, there is no relationship between the single breath and steady state DL in group 3.

A further possible cause of error, giving falsely high results by the single breath method in patients with emphysema, lies in the length of time taken to collect the alveolar sample. In this series the breath-holding time was measured from the beginning of inspiration to the start of sample collection (4). By recalculating DL, using "effective breath-holding time" as suggested by Jones and Meade (21) - namely, from the beginning of inspiration to the endpoint of sample collection, less $3 / 10$ of inspiration time-DL dropped by an average of 10 per cent, but there was still no relationship between the single breath and steady state methods in this group.

2. The steady state De is too low. Marshall (7) has recently discussed the end-tidal sampling method of measuring DL in patients with emphysema. In emphysema, where no clear division exists between dead space and alveolar gas, the end-tidal samples contain more $\mathrm{CO}$ than the mean concentration of $\mathrm{CO}$ in the lungs. The steady state method using end-tidal samples therefore gives falsely low figures for the over-all diffusing capacity of the lung. Bates (22) believes the steady state method with end-tidal sampling reflects the diffusing capacity of the predominantly ventilated portion of the lung.

The most striking difference between groups 2 and 3 is the lack of correlation between the single breath and steady state DL either at rest or on exercise in group 3. Although the mean mixing efficiency index of group 3 (29 per cent) is only slightly lower than that of group 2 (36 per cent), this index is not a sensitive measurement of gas mixing and the differences of gas distribution in the two groups may be greater than that indicated by the mixing index figures. If the ratio $\mathrm{V}_{\mathrm{sb}} / \mathrm{V}_{\text {eq }}$ is used as a measure of mixing efficiency, a much greater difference is found between the two groups. A lower mixing efficiency in group 3 than in group 2 would contribute to the lack of correlation between the two methods in these groups.

3. The main cause of the differences between groups 2 and 3 is probably the inequality of ventilation and perfusion in the emphysematous lung. The volume of unperfused or underperfused lung of emphysema patients is increased, and this increased physiological dead space is ventilated mainly by the tidal volume. When the DL is measured with normal tidal volumes, as in the steady state method, a large proportion of the tidal volume will ventilate physiological dead space and give a low DL. A previous study by Marshall (7) showed that the DL in emphysema was uniform throughout most of a full expiration. The method was not capable of detecting changes in the first few hundred $\mathrm{ml}$ of alveolar gas air, and it is probable that the gas first expired, which has the highest ventilation-perfusion ratio, comes from regions of the lung with a low DL. High values for the single breath $\mathrm{DL}$ with low values by the steady state method could occur when the pathological changes in the lungs are such that the most severely affected parts of the lung are ventilated by the tidal volume and when the re- 
mainder of the lung is less severely affected. When the emphysematous changes in the lungs are diffused throughout the lungs, both the single breath and steady state De will be low.

It appears that in the absence of emphysema either method gives a satisfactory figure for DL. The difference between the results obtained by the two methods can largely be accounted for by the different alveolar volume at which they are measured, although impaired intrapulmonary gas mixing may lower the steady state result by approximately 10 per cent.

In emphysema neither method measures $D_{L}$ satisfactorily. The steady state method gives consistently low results for reasons discussed above and, although this makes the steady state method a useful test clinically, the results do not reflect the true diffusing capacity of the lungs. The single breath method gives results in emphysema which are often optimistic and which, although they may be of value in investigating the physiology of the disease, are usually of little help in the assessment of disability.

\section{SUM MARY}

In 16 normal subjects and 125 patients with cardiac or respiratory disease, measurements of the diffusing capacity of the lungs for carbon monoxide (DL) were made by both the single breath and the steady state methods with end-tidal samples as a measure of alveolar $\mathrm{CO}$.

In 16 normal subjects at rest the steady state De was about 75 per cent of the single breath DL. The steady state DL increased with increasing tidal volume so that at maximal tidal volume the steady state $D_{L}$ was approximately the same as the single breath DL. The increase of $\mathrm{DL}_{\mathrm{L}}$ on exercise was greater than could be accounted for by the increased ventilation on exercise. An increase of respiratory rate without an increase in tidal volume did not increase DL.

The patients with cardiac or respiratory disease were considered in three groups. Group 1 (74 patients with normal pulmonary gas mixing): the steady state DL was 74 per cent of the single breath DL at rest. Group 2 (26 patients with impaired pulmonary gas mixing but no clinical evidence of emphysema): the steady state DL was 66 per cent of the single breath figure. The difference between groups 1 and 2 may be due, in part, to the errors in end-tidal sampling in patients with uneven pulmonary ventilation. Group 3 (25 patients with emphysema) : there was no relationship between the single breath and steady state DL. The reasons for this are discussed.

\section{ACKNOWLEDGMENTS}

We are grateful to Miss Jane Howard and Miss J. A. West for skilled technical assistance, Mr. R. E. Waller for statistical analysis of the results, and the physicians of St. Bartholomew's Hospital for referring cases to us.

\section{REFERENCES}

1. Filley, G. F., MacIntosh, D. J., and Wright, G. W. Carbon monoxide uptake and pulmonary diffusing capacity in normal subjects at rest and during exercise. J. clin. Invest. 1954, 33, 530.

2. Bates, D. V., Boucot, N. G., and Dormer, A. E. The pulmonary diffusing capacity in normal subjects. J. Physiol. (Lond.) 1955, 129, 237.

3. Krogh, A., and Krogh, M. On the rate of diffusion of carbonic oxide into the lungs of man. Skand. Arch. Physiol. 1910, 23, 236.

4. Ogilvie, C. M., Forster, R. E., Blakemore, W. S., and Morton, J. W. A standardized breath holding technique for the clinical measurement of the diffusing capacity of the lung for carbon monoxide. J. clin. Invest. 1957, 36, 1 .

5. Forster, R. E. Exchange of gases between alveolar air and pulmonary capillary blood: Pulmonary diffusing capacity. Physiol. Rev. 1957, 37, 391.

6. Marks, A., Cugell, D. W., Cadigan, J. B., and Gaensler, E. A. Clinical determination of the diffusion capacity of the lungs. Comparison of methods in normal subjects and patients with "alveolar-capillary block" syndrome. Amer. J. Med. 1957, 22, 51.

7. Marshall, R. A comparison of methods of measuring the diffusing capacity of the lungs for carbon monoxide. Investigation by fractional analysis of the alveolar air. J. clin. Invest. 1958, 37, 394.

8. Linderholm, $\mathrm{H}$. On the significance of $\mathrm{CO}$ tension in pulmonary capillary blood for determination of pulmonary diffusing capacity with the steady state CO method. Acta med. scand. 1957, 156, 413.

9. Sjöstrand, T. A method for the determination of carboxyhaemoglobin concentrations by analysis of alveolar air. Acta physiol. scand. 1948, 16, 201.

10. Henderson, M., and Apthorp, G. H. A rapid method for the estimation of carbon monoxide in blood. Brit. med. J. 1960, 2, 1853.

11. Forster, R. E., Roughton, F. J. W., Cander, L., Briscoe, W. A., and Kreuzer, F. Apparent pulmonary diffusing capacity for $\mathrm{CO}$ at varying alveolar $\mathrm{O}_{2}$ tensions. J. appl. Physiol. 1957, 11, 277.

12. Bates, D. V., and Christie, R. V. Intrapulmonary mixing of helium in health and in emphysema. Clin. Sci. 1950, 9, 17. 
13. Cournand, A. The syndrome of "alveolar-capillary block": Clinical, physiologic, pathologic and therapeutic considerations. Proc. Roy. Coll. Phys. Surg., Canada, 1952, pp. 34-47.

14. Bates, D. V., Knott, J. M. S., and Christie, R. V. Respiratory function in emphysema in relation to prognosis. Quart. J. Med. 1956, 25, 137.

15. Ross, J. C., Frayser, R., and Hickam, J. B. A study of the mechanism by which exercise increases the pulmonary diffusing capacity for carbon monoxide. J. clin. Invest. 1959, 38, 916.

16. Turino, G. M., Brandfonbrener, M., and Fishman, A. P. The effect of changes in ventilation and pulmonary blood flow on the diffusing capacity of the lungs. J. clin. Invest. 1959, 38, 1186.

17. MacNamara, J., Prime, F. J., and Sinclair, J. D. The increase in diffusing capacity of the lungs on exercise: An experimental and clinical study. Lancet 1960, i, 404.
18. Shephard, R. J. "Breath-holding" measurement of carbon monoxide diffusing capacity. Comparison of field test with steady-state and other methods of measurement. J. Physiol. (Lond.) 1958, 141, 408.

19. McGrath, M. W., and Thomson, M. L. Effect of age, body size and lung volume change on alveolarcapillary permeability and diffusing capacity in man. J. Physiol. (Lond.) 1959, 146, 572.

20. Cugell, D. W., Marks, A., Ellicott, M. F., Badger, T. L., and Gaensler, E. A. Carbon monoxide diffusing capacity during steady exercise. Amer. Rev. Tuberc. 1956, 74, 317.

21. Jones, R. S., and Meade, F. Pulmonary diffusing capacity: An improved single-breath method. Lancet 1960, i, 94.

22. Bates, D. V. The measurement of the pulmonary diffusing capacity in the presence of lung disease. J. clin. Invest. 1958, 37, 591. 